\title{
Clinical Profile and Management of PDA in Neonates
}

\author{
C.C. Shanthala, P.P Maiya, D. Vishwanath, Naveen Banakappa, P. Mallikarjuna \\ Swamy, Nagaraj Desai, Ravikishore and K.H. Srinivas
}

Division of Neonatology, Departments of Pediatrics and Cardiology, M.S. Ramaiah Medical College, Bangalore

\begin{abstract}
Patent ductus arteriosus (PDA) is recognised more often with increasing survival of preterm babies. The pharmacological closure of ductus by indomethacin has changed the management of PDA'. Twenty neonates admitted over a period of 21 months to Neonatal Intensive Care Unit (NICU) of M.S. Ramaiah Medical College hospital, Bangalore, who were diagnosed to have PDA, were analyzed. The objectives of this retrospective analysis were to study the clinical profile, the efficacy of oral indomethacin and the outcome of PDA. 2-D and Doppler echocardiaography were used to confirm the clinically suspected PDA. These neonates were treated with 3 doses of oral indomethacin $(0.2-0.25 \mathrm{mg} / \mathrm{kg} /$ dose 12 hourly) along with fluid restriction and oxygen. Echocardiography was repeated to demonstrate the closure of PDA. The incidence of PDA was $2.3 \%$ of total NICU admissions. Seventy percent of this cohort were $<32$ weeks of gestation, $55 \%$ had birth weight of $<1500$ gms. Seventy percent (14) neonates had onset of PDA after $48 \mathrm{hrs}$ of life. $81.25 \%$ of neonates responded to indomethacin and overall survival rate in treated group was $67 \%$. Drug related complications were noted in 2 newborns.

This study illustrates the utility of echocardiography in diagnosing and monitoring PDA in preterm and low birth weight babies with high index of suspicion of this common congenital heart disease. Pharmacological intervention with indomethacin is rewarding with acceptable results. (Indian J Pediatr 1997; 64 : 667-670)
\end{abstract}

Key words : Patent ductus arteriosus; Indomethacin; Doppler echocardiography.

The advances in neonatal intensive care have significantly improved the survival of preterm babies. High prevalence of PDA (18-80\%) amongst preterm has made it a challenging problem to neonatologists and cardiologists ${ }^{2,3}$. Factors influencing the persistence of ductus in preterms are diminished response to constricting effects of oxygen and increased sensitivity of immature ductus to dilating properties of prostaglandins ${ }^{4}$. In addition, PDA can com-

Reprint requests : Dr. P.P. Maiya, Professor \& HOD of Pediatrics, M.S. Ramaiah Medical College Hospital Gokula, Bangalore 560054. plicate variety of diseased states in the newborns. PDA with a large left to right shunt leads to complications like cardiac failure, necrotising enterocolitis (NEC), germinal matrix hemorrhage and increases the risk of bronchopulmonary dysplasia in preterm babies with respiratory distress syndrome (RDS) ${ }^{5}$.

Indomethacin therapy for closure of PDA was first described in 1976 and since then has been documented to be a safe and effective method for closure of PDA ${ }^{4,6}$. Hence, early clinical recognition of symptomatic PDA and pharmacological intervention with indomethacin is useful in de- 
creasing the morbidity and mortality.

\section{MATERIAL AND METHODS}

This study comprises 29 newborns admitted to the NICU of M.S. Ramaiah Medical Teaching Hospital, Bangalore, during the period July 1992 through August 1994, who were diagnosed to have PDA. The birth weight, gestational age and clinical parameters were recorded at admission.

The diagnosis of PDA was based on systolic murmur, bounding pulse, tachycardia, hyperactive pericardium and cardiac failure. Apnoea, hypercapnia and sudden deterioration in the respiratory status in babies who were ventilated for RDS were other manifestions seen in these neonates.

The diagnosis of PDA was confirmed in all by 2-D and Doppler echocardiography by : (1) continuous flow in main pulmonary artery (MPA) on pulse doppler echocardiography (PSAX view). (2) imaging of ductus by colour flow mapping (PSAX \& suprasternal long axis view). Sepsis, metabolic and hematological screening were done in all cases.

A maximum of three doses of oral indomethacin in the dose of $0.2-0.25 \mathrm{mg} /$ $\mathrm{kg} /$ dose was given 12 th hourly, after studying the platelet count and renal function. Oral preparation was made by suspending a $25 \mathrm{mg}$ capsule of indomethacin in $10 \mathrm{ml}$ of normal saline and was administered through nasogastric tube. Supportive treatment included fluid restriction, temperature homeostasis, oxygen and antibiotics. Four newborns were not given indomethacin because of thromobocytopenia, necrotising enterocolitis (NEC) and renal failure. Echocardiography was repeated in all cases, 48-72 hours after the completion of therapy.

\section{RESULTS}

PDA occurred in $2.3 \%$ of total NICU admissions and $4.47 \%$ of preterm admissions to the NICU during this period. Male to female ratio was $1: 1.2$. PDA was diagnosed during the first week of life in 14 babies and in 4 after the 7 th postnatal day.

Table 1 shows prevalence of PDA with respect to the gestational age and birth weight. Mean gestational age was 31 weeks and mean birth weight was 1551 grams. Table 2 shows the underlying conditions in babies with PDA.

The major presenting. features were systolic murmur (100\%), bounding pulses $(40 \%)$, tachycardia $(40 \%)$, cardiac failure $(45 \%)$ and hypoxia. PDA was diagnosed in 11 preterms with RDS who were receiving ventilator support.

Table 3 shows the outcome of

TABle 1. PDA in Relation to the Birth Weight and Genstational Age ( $\mathrm{N}=20)$

\begin{tabular}{llllll}
\hline $\begin{array}{l}\text { Birth weight } \\
\text { (grams) }\end{array}$ & \multicolumn{5}{c}{ Gestational age (week) } \\
\cline { 2 - 6 } & $<32$ & $33-36$ & $>37$ & Total & $\%$ \\
\hline $1001-1500$ & 10 & 01 & 00 & 11 & 55 \\
$1501-2000$ & 02 & 02 & 01 & 05 & 25 \\
$2001-2500$ & 02 & 01 & 01 & 04 & 20 \\
\hline Total (\%) & $14(70)$ & $04(20)$ & $02(10)$ \\
\hline
\end{tabular}

TABLe 2. Underlying Problems

\begin{tabular}{ll}
\hline HMD & 11 \\
Sepsis & 12 \\
MAS & 01 \\
Pneumonia & 04 \\
Heamatological problems & 04 \\
Hyperbilirubinemia & 14 \\
\hline
\end{tabular}


TABlE 3. Postnatal Age and Response to Therapy $(\mathrm{N}=16)$

\begin{tabular}{lcc}
\hline $\begin{array}{l}\text { Day of } \\
\text { (PND) }\end{array}$ & $\begin{array}{c}\text { Starting the } \\
\text { treatment }\end{array}$ & Closure \\
\hline $0-1$ & 1 & 1 \\
$2-4$ & 3 & 3 \\
$5-7$ & 7 & 6 \\
$8-10$ & 2 & 2 \\
$11-12$ & 2 & 1 \\
$13-14$ & 0 & 0 \\
$>14$ & 1 & 0 \\
\hline
\end{tabular}

indomethacin therapy.

Of the four babies who were not given indomethacin, two were clinically unstable and died due to sepsis soon after the detection of PDA. The third died due to sepsis and had received only one dose of indomethacin. The other baby did not receive the drug due to thrombocytopenia. None of the babies who survived had drug related complications.

Eleven (67\%) out of 16 babies who received indomethacin survived. Five neonates, who died after the completion of therapy, had fulminant sepsis and related complications though two babies had drug related complications.

\section{DISCUSSION}

The incidence noted in our NICU was $2.3 \%$ of total admissions and $4.47 \%$ of preterm admissions. As ours is a referral centre, this may not reflect true incidence. The reported incidence is 2.48 cases per 1000 live briths?.

PDA is a common accompaniment of prematurity ${ }^{8}$ as seen in our study. The occurrence was also high in babies with birth weight less than 1500 grams. The incidence is inversely related to gestational age and birth weight. This was brought out in a large multicentric study which reported an incidence of PDA as $20 \%$ in < 1750 grams of birth weight, $42 \%$ at $500-999$ grams, $21 \%$ at $1000-1499$ grams and $7 \%$ at $1500-1750$ grams. The risk was reported to be higher in neonates dependent on ventilatory care $^{10}$.

The occurrence of PDA was maximum $(70 \%)$ during the first week of life. Six babies who required ventilatory support for RDS, developed PDA during the 1st week of life. The opening of PDA during the recovery phase of respiratory distress syndrome is well documented in many studies $^{11}$. This is attributed to the reduction in cholinergic innervation of the ductus and decreased ductal responsiveness to oxygen and poor myocardial reserves. PDA is also dependent on the factors which alter the pulmonary vascular resistance. In those receiving assisted ventilation, PDA was diagnosed on the basis of persistent hypoxia, deterioration of ventilatory status requiring changes in the ventilatory settings. This is known to be a good indicator of left to right shunt through ductus ${ }^{1}$. Classical murmur of PDA may not always be present, a high index of suspicion is essentional for diagnosing PDA in ventilated neonates. 2$D$ echocardiography was useful in the diagnosis and confirmation of closure of the ductus. The same clinical and echocardiographic criteria have been used by many workers ${ }^{12}$.

Conventional medical treatment of PDA includes fluid restriction, decongestive therapy, followed by trial of indomethacin. Until recently, frusemide was widely used in the initial management of PDA. Now frusemide has been shown to promote ductal dilatation by stimulating prostagladin synthesis which in turn may decrease the efficacy of subsequent indomethacin thera- 
$\mathrm{py}^{13}$. Indomethacin has been shown to be effective in pharmacological closure of ductus in various studies ${ }^{4,6}$. Hence, instead of frusemide, oral indomethacin was tried along with fluid restriction. Various solutions to dissolve indomethacin for orogastric administration have been described. Suspending the drug in the saline or water may be simplet.

In our study, $81.25 \%$ of neonates had successful closure of the ductus after indomethacin therapy $(7.7 \%, 23 \%, 69.2 \%$, following 1st, 2nd, 3rd dose respectively) as compared to $79-96 \%$ success rate in various studies ${ }^{1,14}$. Indomethacin appears to be safe as none who responded to the drug in our study had serious complications related to indomethacin.

All infants who are at a risk of developing PDA should be assessed carefully for the evidence of PDA, as early treatment with indomethacin will affect the outcome. Echocardiographic evaluation is useful to confirm the diagnosis and also to rule out duct dependent lesions. Indomethacin therapy is safe and rewarding in pharmacological closure of ductus in symptomatic newborns.

\section{REFERENCES}

1. Tsu F. Yeh and Ian Carr. Pharmacologic Closure of Patent Ductus Arteriosus in Drug Therapy in the Neonatal and Small Infant Year Book Medical Publishers, $1985: 116-130$.

2. Siass, B et al. Incidence and clinical features of patent ductus arteriosus in low birth weight infants, a prospective analysis of 150 consecutively born infants. Pediatrics 1976; $57: 347-351$

3. Yeh TF et al. Intravenous indomethacin therapy in premature infants with persistent ductus arteriosus : a double blind controlled study. I Pediatr 1981 a; $98: 136-145$.

4. Heymann MA, Rudolph AM, Silvermann
$\mathrm{NH}$. Closure of the ductus arteriosus in premature infants by inhibition of prostaglandin synthesis. N Engl J Med 1976; $295: 530-533$.

5. Brown ER. Increased risk of bronchopulmonary dysplasia in infants with patent ductus arteriosus. J Pediatr 1979; 95 : 865866.

6. Friedman WF, Hirschklan MJ, Printz MP et al. Pharmacological closure of patent ductus arteriosus in the premature infants. N Engl J Med 1976; 295 : 526-529.

7. A. Shenoi, A. Narang, O.N. Bhakoo, P.S. Bidwai. Clinical profile and management of symtomatic patent ductus arteriosus in premature infants. Indian Pediatrics 1991; $28: 125-130$.

8. Nick Archer. Patent Ductus Arteriosus in the Newborn. Arch Dis Child 1993; 69 : 529-532.

9. Ellison RC, Peckham GL, Lang $P$ et al. Evaluation of the preterm infant for patent ductus arteriosus. Pediatrics 1983; 71 : 364-372.

10. Cotton RB, Stahlman MT, Kovar I, Catterton W2. Medical management of small preterm infants with symptomatic

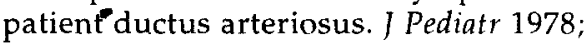
$92: 467-474$.

11. Blanco EC, Siasi B and Cabal LA. Persistent patency of ductus arteriosus in premature newborn infants, Am I cardiol (abst) 1973; $31: 120$.

12. Gentile R, Stevenson G, Dooley T, Franklin D, Kawabori I, Pearlman A. Pulsed Doppler echocardiographic determination of time of ductal closure in normal newborn infants. I Pediatr 1981; 98 : 443448.

13. Friedman $Z$, Demers LM, Marks KH, Uhrmann S, Maisels MJ. Urinary excretion of prostaglandin $\mathrm{E}$ following the administration of furosemide and indomethacin to sick low birth weight infants. J Pediatr 1978; 93 : 512-515.

14. Gersony WH, Peckham GH, Ellison RC et al. Effect of indomethacin in premature infants with Patent-ductus arteriosus, Results of National Collaborative study. I Pediatr 1983; $102: 895$. 